\section{Application of microsatellite markers to confirm controlled crosses and assess genetic identity in common bean}

\author{
Samara Rayane Pereira de Morais ${ }^{1}$, Ariadna Faria Vieira², Laura \\ Cristina da Silva Almeida ${ }^{1}$, Luana Alves Rodrigues ${ }^{3}$, Patrícia \\ Guimarães Santos Melo ${ }^{1}$, Luís Cláudio de Faria ${ }^{3}$, Leonardo \\ Cunha $\mathrm{Melo}^{3}$, Helton Santos Pereira ${ }^{3}$ and Thiago Lívio Pessoa \\ Oliveira de Souza ${ }^{3 *}$
}

\begin{abstract}
This manuscript reports on the application of microsatellite markers to assess the effectiveness of controlled crosses and assess the genetic identity of seed samples from a same common bean cultivar (BRS Estilo). The DNA was extracted from leaf tissue collected from $F_{1}$ plants and their parents as well as from seed samples of the cv. BRS Estilo by the alkaline lysis method. In all cases, genotyping was carried out with 24 microsatellite markers distributed in four multiplex panels with six markers each. Of the $392 F_{1}$ plants analyzed, obtained from 21 different biparental crosses, 325 (82.91\%) was confirmed as real hybrids by the molecular analysis. The genetic analysis of the four BRS Estilo seed samples (two of certified seeds and two of saved seeds) detected $100.00 \%$ genetic identity with the samples used as control in only one certified seed sample.
\end{abstract}

Key words: Phaseolus vulgaris, molecular markers, genetic similarity, markerassisted selection, plant breeding.

\section{INTRODUCTION}

Common bean (Phaseolus vulgaris L.) is an agronomic legume species with key importance for the world, because of its wide use as staple food, especially in developing countries in Africa and Latin America (Broughton et al. 2003). Brazil is currently one of the leading producers and the world's largest consumer of common bean with a grain production of 2.7 million tons in 2014, on an acreage of 1.94 million hectares, resulting in an average yield of approximately $1,400 \mathrm{~kg}$ ha-1 (http://www.cnpaf.embrapa.br/socioeconomia/index.htm). Nevertheless, there are many factors that limit the crop performance in the country, related to the cropping system, distribution and marketing of the product, as well as associated with regional preferences. There are also other crop-related factors which can be addressed by breeding, such as grain yield and quality, resistance to pests and diseases, plant architecture and lodging, earliness, efficient biological nitrogen fixation and nutrient uptake, and tolerance to drought and heat (Barros and Souza 2012).

In the early 80 s, with the introduction and more routine use of molecular genetic techniques, various types of molecular markers were tested, which
Crop Breeding and Applied Biotechnology 16: 234-239, 2016 Brazilian Society of Plant Breeding. Printed in Brazil http://dx.doi.org/10.1590/198470332016v16n3n35 
proved useful as tools to assist and optimize the different stages of plant breeding programs. Among these markers are microsatellites, widely used in studies on genetic diversity and mapping, due to the simplicity, high repeatability and informative content of this technique, and for being codominant and multi-allelic (Muller et al. 2014).

The number of populations generated annually by crosses in the scope of a nationwide plant breeding programs is quite considerable. Thus, the use of molecular tools that can enhance or monitor this process is particularly important. Alzate-Marin et al. (1996) have already demonstrated the efficiency of RAPD (Random Amplified Polymorphic DNA) markers for the confirmation of biparental crosses between genetically close parents of common bean and soybean without phenotypic contrast in readily assessable morphological traits. Another important stage of plant breeding programs is the confirmation of the identity and genetic purity of the genotypes during the seed production process, which can also be monitored or improved with molecular markers.

The main goal of this study was to evaluate the efficiency of controlled biparental crosses in common bean and assess the genetic identity of BRS Estilo seed samples using microsatellite markers.

\section{MATERIAL AND METHODS}

\section{Plant material}

In the framework of the common bean breeding program conducted by Embrapa and partners, $392 \mathrm{~F}_{1}$ plants resulting from 21 different biparental crosses performed under controlled conditions were evaluated. The purpose of these crosses was to develop segregating populations for inheritance studies and mapping of genes or QTLs (Quantitative Trait Loci) associated with disease resistance and slow darkening of grains of the Carioca market class.

Four seed samples of cv. BRS Estilo (Melo et al. 2010) were obtained from common bean growers of traditional producing areas in the State of Goiás. These samples represent four separate lots, two of certified seeds and two of saved seeds (grains used as seeds). All seed samples were analyzed regarding their genetic identity, using as reference two control samples consisting of genetic seed of BRS Estilo provided by Embrapa Arroz e Feijão, the developing institution and custodian of the cv. BRS Estilo. The tested samples and controls consisted of $1.0 \mathrm{~kg}$ of seeds each. It is noteworthy that during the breeding process for the development of BRS Estilo, plants were selected in the $F_{5}$ and again in the $F_{8}$ generation, as described by Melo et al. (2010). The common bean line 'LM 98202709', the original identification of BRS Estilo, was selected in the $\mathrm{F}_{8: 9}$ generation. This indicates that BRS Estilo is in fact a line of which all loci, or something very close to $100 \%$ of the loci, are expected to be homozygous.

\section{DNA extraction and analysis with molecular markers}

The DNA was extracted from leaf tissue samples of $F_{1}$ plants and their parents and from seed samples of $c v$. BRS Estilo using the alkaline lysis method, as described by Xin et al. (2003), but with the modifications proposed by Valdisser et al. (2013). For DNA extraction from seeds, subsamples of $5.0 \%$ of the total weight of the initial samples $(50 \mathrm{~g})$ were weighed and ground in the laboratory, i.e., one subsample of $50 \mathrm{~g}$ for each initial $1.0 \mathrm{~kg}$ sample, using a portable mill, model IKA A11 basic (IKA Werke GmbH \& Co.).

In the molecular marker analyses, DNA samples from all parents were first analyzed using 24 microsatellite markers distributed in four multiplex panels with six markers each (Valdisser et al. 2013) (Table 1). For the genotyping of the resulting $F_{1}$ plants, at least one marker identified as polymorphic among the parents of each population was used to check the hybrid nature of those plants. The amplification reactions of the DNA from all tested plants were performed by multiplex PCR, with a final volume of $5.0 \mu \mathrm{L}$, as described by Valdisser et al. (2013). Capillary electrophoresis of the DNA amplified products was performed with an ABI 3500xL sequencer (Applied Biosystems), always using a marker with known molecular weight, the GeneScan 500 ROX Size Standard (Life Technologies). The final genotyping (allele calling) was performed with software GeneMapper (Applied Biosystems).

For the genetic identity analysis of four BRS Estilo seed samples, the genetic similarity of these samples was estimated in relation to the control samples consisting of genetic seeds of the cultivar. Of the 24 microsatellite markers used in the analyses those that generated clear and robust polymorphisms were considered. Subsequently, the alleles detected among the tested seed samples were coded in a data matrix which was used to calculate the estimates of genetic similarity (SGij), based on the simple matching coefficient using the software Genes (Cruz 2013). 
Table 1. Microsatellite markers grouped in four panels used for molecular characterization of common bean, with the identification of the loci, their respective fluorescence, amplification range in base pairs (bp), primer sequences, and genome location

\begin{tabular}{|c|c|c|c|c|c|c|}
\hline Panel & Marker & $\begin{array}{l}\text { Fluores- } \\
\text { cence }\end{array}$ & $\begin{array}{c}\text { Amplification } \\
\text { range (pb) }\end{array}$ & Primer F & Primer $\mathbf{R}$ & $\begin{array}{c}\text { Chromo- } \\
\text { some }^{\text {a }}\end{array}$ \\
\hline \multirow[t]{4}{*}{1} & BM143 & HEX & $100-170$ & GGGAAATGAACAGAGGAAA & ATGTTGGGAACTTTTAGTGTG & Pv02 \\
\hline & PVBR25 & 6-FAM & $140-180$ & GAGCTTCTCCGTCCTGTGT & CGAACTGAATCAGAAAGGAA & Pv09 \\
\hline & BM114 & 6-FAM & $230-260$ & AGCCTGGTGAAATGCTCATAG & CATGCTTGTTGCCTAACTCTCT & Pv09 \\
\hline & BM138 & NED & $190-210$ & TGTCCCTAAGAACGAATATGGAATC & GAATCAAGCAACCTTGGATCATAAC & Pv05 \\
\hline \multirow{5}{*}{2} & PVBR35 & 6-FAM & $190-260$ & TCTACGCGTTCCCTCTGTCT & AGTGGATGTGTGGGAAAAGC & Pv04 \\
\hline & BM202 & 6-FAM & $100-173$ & ATGCGAAAGAGGAACAATCG & СCTTTACCCACACGCCTTC & Pv11 \\
\hline & BM189 & NED & $80-120$ & СТСССАСТСТСАСССТСАСТ & GCGCCAAGTGAAACTAAGTAGA & Pv03 \\
\hline & BM210 & NED & $160-220$ & ACCACTGCAATCCTCATCTTTG & СССТСАТССТССАТТСТTATCG & Pv07 \\
\hline & BM155 & HEX & $100-145$ & GTTCATGTTTGTTTGACAGTTCA & CAGAAGTTAGTGTTGGTTTGATACA & Pv05 \\
\hline \multirow{3}{*}{3} & PVBR272 & 6-FAM & $70-135$ & CAGAACAGAAGAAGAAACAGAAAATG & GCGTGTTCCTCTGTGTGTGT & Pv02 \\
\hline & BM154 & 6-FAM & $205-317$ & TCTTGCGACCGAGCTTCTCC & CTGAATCTGAGGAACGATGACCAG & Pv09 \\
\hline & PVBR13 & 6-FAM & $159-200$ & TGAGAAAGTTGATGGGATTG & ACGCTGTTGAAGGCTCTAC & Pv06 \\
\hline \multirow[t]{6}{*}{4} & PVBR11 & HEX & $175-192$ & AAACTCAAAGTCGTTGTTCC & CCACTGACTCTAGCTCCTCC & Pv02 \\
\hline & BM181 & NED & $170-250$ & CAACAGTTAAAGGTCGTCAAATT & CCACTCTTAGCATCAACTGGA & Pv05 \\
\hline & BM183 & 6-FAM & $130-170$ & CTCAAATCTATTCACTGGTCAGC & TCTTACAGCCTTGCAGACATC & Pv07 \\
\hline & PVBR163 & 6-FAM & $180-350$ & TGAGAGTGGAGAAGGAGAGAGA & TGACAACACTGCAAACACCA & Pv06 \\
\hline & BM201 & NED & $90-120$ & TGGTGCTACAGACTTGATGG & TGTCAССТСТСТССТССААT & Pv01 \\
\hline & PVBR251 & HEX & $193-220$ & TGAAGTTGCAGCTAGGTTGG & GGTTGTGCTTGTGTTGTT GG & Pv01 \\
\hline
\end{tabular}

a Genome location based on mapping results (Grisi et al. 2007), the PhaseolusGenes database (http://phaseolusgenes.bioinformatics.ucdavis.edu/) or BLAST analysis using the reference genome of Phaseolus vulgaris (Schmutz et al. 2014).

a)

b)

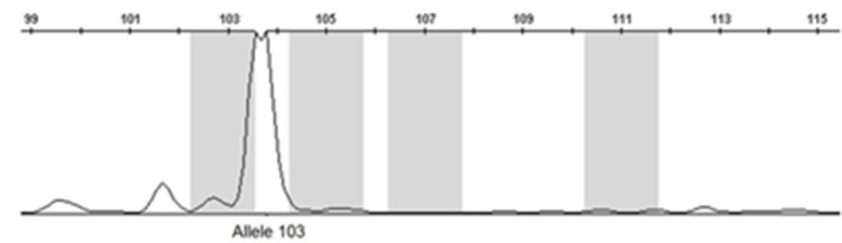

c)
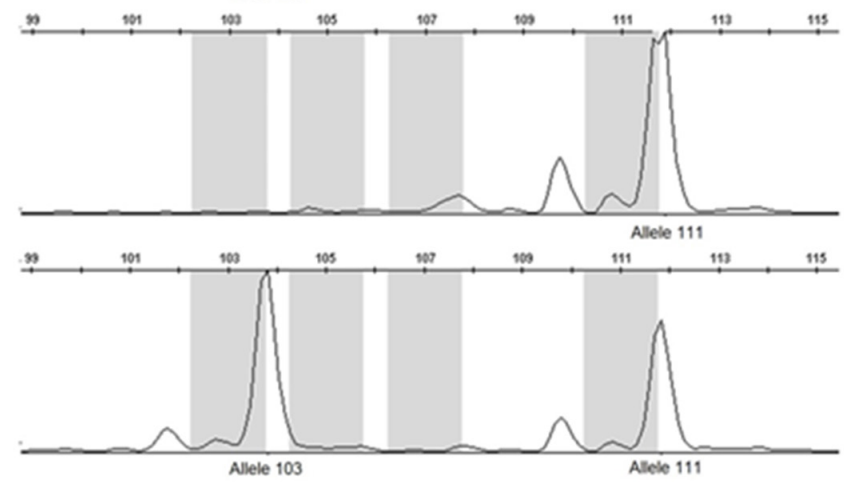

Figure 1. DNA amplification profile of common bean genotypes used as contrasting parents for anthracnose reaction with the microsatellite marker BM 189. a) Female parent presenting only allele 103 of BM 189 (homozygous); b) male parent presenting only allele 111 of BM 189 (homozygous); and c) F plant presenting both alleles, 103 and 111 of BM 189 (heterozygous), confirming its hybrid nature. 


\section{RESULTS AND DISCUSSION}

The hybrid nature of 325 (82.91\%) of the 392 analyzed $F_{1}$ plants, derived from 21 different biparental crosses, was confirmed by the molecular analysis (Table 2). The microsatellite loci identified as polymorphic among their parents were heterozygous in these plants, that is, they contained two alleles, each specifically from one of the parents (Figure 1). The remaining 67 analyzed plants (17.09\%) were originated by selfing, for containing only the same allele or homozygous genotype as the female parent. For the breeding program for anthracnose, the success rate of hybridization was $92.41 \%$ (207/224), for angular leaf spot $61.64 \%$ (45/73), for fusarium wilt 53.85\% (21/39), and for slow darkening $92.86 \%(52 / 56)$. The variation in success rate of the four different programs was from 53.85 to $92.86 \%$, and of the 21 tested biparental crosses from 33.33 to $100.00 \%$ (Table 2 ).

These results demonstrate the efficiency of the microsatellite markers used in this study to confirm common bean crosses. These markers allow the distinction between effective and ineffective crosses, avoiding a bias caused by plants originated by selfing. This would result in a loss of time and financial resources and produce inconsistent and misleading results about the genetic structure of the studied populations. The results further showed that this confirmation becomes essential when segregating populations are developed to be used in studies where the genetic structure of these populations must be preserved, e.g., in inheritance studies and gene/QTL mapping. In addition, based on the variation of the hybridization rate observed between the different crosses (Table 2), the effectiveness of the crosses did not only depend on the environmental conditions at the moment of the cross and on the experience and training of the cross operator, but also on the genetic suitability or compatibility among the parent genotypes.

In the analysis of the genetic identity of BRS Estilo seed samples, 22 of the 24 initially selected microsatellite loci were used, for having clearly evident and robust polymorphisms. Thus, these 22 loci were effectively used to estimate

Table 2. Common bean breeding programs, crosses, number of evaluated $F_{1}$ plants, number of obtained hybrids and hybridization rate between common bean genotypes that do not differ among each other based only on morphological traits, estimated using microsatellite markers

\begin{tabular}{|c|c|c|c|c|}
\hline Program & Cross & No. of $F_{1}$ plants & No. of hybrids & Hybridization rate (\%) \\
\hline \multirow{6}{*}{ Anthracnose (ANT) } & BRSMG Realce × CNFC15826 & 36 & 35 & 97.22 \\
\hline & BRS Pontal × Rosinha G2 & 35 & 35 & 100.00 \\
\hline & BRS Horizonte $\times$ Rosinha G2 & 17 & 14 & 82.35 \\
\hline & BRS Cometa $\times$ Rosinha G2 & 21 & 19 & 90.48 \\
\hline & BRS Horizonte $\times$ BRS Cometa & 115 & 104 & 90.43 \\
\hline & Total ANT & 224 & 207 & 92.41 \\
\hline \multirow{5}{*}{ Angular leaf spot (ALS) } & CNFC $15097 \times$ BRS Horizonte & 8 & 6 & 75.00 \\
\hline & CNFC 15097 × BRS Cometa & 3 & 2 & 66.67 \\
\hline & CNFC $15082 \times$ BRS Horizonte & 22 & 12 & 54.55 \\
\hline & CNFC $15082 \times$ BRS Cometa & 1 & 1 & 100.00 \\
\hline & Total ALS & 73 & 45 & 61.64 \\
\hline \multirow{2}{*}{ Fusarium wilt (FSW) } & CNFP 10794 × BRS Supremo & 7 & 3 & 42.86 \\
\hline & Total FSW & 39 & 21 & 53.85 \\
\hline \multirow{7}{*}{ Slow darkening (SDK) } & BRSMG Madrepérola $\times$ CNFM 11940 & 5 & 3 & 60.00 \\
\hline & BRSMG Madrepérola × 1533-15 & 6 & 6 & 100.00 \\
\hline & BRSMG Madrepérola $\times$ AN512666-0 & 12 & 12 & 100.00 \\
\hline & CNFM $11940 \times 1533-15$ & 13 & 13 & 100.00 \\
\hline & CNFN $11940 \times$ AN512666-0 & 10 & 8 & 80.00 \\
\hline & $1533-15 \times$ AN512666-0 & 10 & 10 & 100.00 \\
\hline & Total SDK & 56 & 52 & 92.86 \\
\hline Total & & 392 & 325 & 82.91 \\
\hline
\end{tabular}


the genetic similarity of the four seed sources tested in the present work in relation to the control samples formed by genetic seeds of the cv. BRS Estilo.

Of the four seed sources tested, in only one $100.00 \%$ genetic identity with the two control samples was observed, both of which also presented $100.00 \%$ relative genetic similarity to each other (Figure 2 ). This source consisted of a lot of certified seed. However, the genetic identity of the other certified seed sample was estimated at $93.00 \%$, indicating a potential mixture with other genotypes with similar phenotypic patterns of plants and seeds, possibly undetectable by conventional genetic purity tests. Neither sample of saved seed was totally similar to the control samples, with estimates of genetic similarity of 87.00 and $91.00 \%$ (Figure 2 ). This result demonstrates that the use of uncertified seeds by the common bean growers represents a real risk, since the genetic identity of a considerable part of the plantation will be unknown, enabling potential discrepancies between plants in terms of yield, environmental adaptation, cycle, and reaction to pests and diseases. Thus, these results also reinforce the importance of using certified seed from a reliable origin.

The advantages of using molecular markers in plant breeding programs over the use of only phenotypic or morphological markers lie in the fact that molecular markers are unlimited in number, usually easily detectable, generate a high level of polymorphism between tested genotypes, are neutral in relation to environmental effects, with little or no effect of epistasis or pleiotropy, and generally behave as traits with simple and predictable inheritance (Barros and Souza 2012).

This study demonstrates the efficiency of microsatellite markers as useful tools to support key decision-making phases in common bean breeding programs. The panel of 24 microsatellite loci used in this study is being routinely used at different stages of the common bean breeding program conducted by Embrapa and partners. In addition to the confirmation of controlled crosses and the detection of genetic identity of genotypes, other microsatellite marker applications include studies of genetic diversity among parents and elite lines, monitoring of allelic diversity and genetic representation of parents in breeding populations obtained by backcrosses and recurrent selection, aside from the control of genetic purity during the seed production process (Batista et al. 2014, Cardoso et al. 2014). It is worth mentioning that this molecular tool is available for immediate adoption and use by other common bean breeding programs in Brazil and worldwide.

In Brazil, marker-assisted selection is only routinely used in breeding programs of plant species of high commercial value, such as soybean, maize and cotton, in particular those led by the private sector. For common bean, although several markers and examples of application in the academic context are available, the routine use is only just being implemented. Thus, this study is an interesting example of the effective application of molecular markers in routine activities of a national common bean breeding program, led by a public research institution. Thousands of SNP (Single Nucletide Polymorphism) markers are currently available for common bean. This number increased greatly due to the recent publication of the genome sequence of the species (Phaseolus vulgaris v1.0; http://www.phytozome.net) (Schmutz et al. 2014). Therefore, efforts are currently under way at Embrapa Arroz e Feijão to develop DNA chips and genotype panels using SNP markers for genetic analysis and marker-assisted selection.

\section{ACKNOWLEDGEMENTS}

The authors would like to thank the Universidade Federal de Goiás and Embrapa Arroz e Feijão for the opportunity to develop this work, and are indebted to the entire research team of the common bean breeding program conducted by Embrapa and partners for the constant support. The authors are also grateful to the Conselho Nacional de Desenvolvimento Científico e Tecnológico (CNPq), for scholarships for undergraduate students and for technological development and innovative extension. 


\section{REFERENCES}

Alzate-Marin AL, Baía GS, Martins-Filho S, Paula-Júnior TJ, Sediyama CS, Barros EG and Moreira MA (1996) Use of RAPD-PCR to identify true hybrid plants from crosses between closely related progenitors. Brazilian Journal of Genetics 19: 621-623.

Barros EG and Souza TLPO (2012) Biotecnologia na cultura do feijoeiro. In Cançado GMA and Londe LN (eds) Biotecnologia aplicada à agropecuária. Editora Epamig, Caldas, p. 351-370.

Batista CEA, Bueno LG, Resende TN, Lima VR, Wendland A, Pereira HS, Faria LC, Melo LC Souza TLPO (2014) Parental genetic representativeness in black seeded common bean progenies from the Embrapa recurrent selection program for tolerance to BGMV. Annual Report of the Bean Improvement Cooperative 57: 221-222.

Broughton WJ, Hernández G, Blair M, Beeb S, Gepts P and Vanderleyden J (2003) Beans (Phaseolus spp.) - model food legumes. Plant and Soil 252: 55-128.

Cardoso PCB, Brondani C, Menezes IPP, Valdisser PAMR, Borba TCO, Del Peloso MJ and Vianello RP (2014) Discrimination of common bean cultivars using multiplexed microsatellite markers. Genetics and Molecular Research 13: 1964-1978.

Cruz CD (2013) GENES - a software package for analysis in experimental statistics and quantitative genetics. Acta Scientiarum Agronomy 35: $271-276$.

Grisi MCM, Blair MW, Gepts P, Brondani C, Pereira PAA and Brondani RPV (2007) Genetic mapping of a new set of microsatellite markers in a reference common bean (Phaseolus vulgaris) population BAT93 $\times$ Jalo EEP558. Genetics and Molecular Research 6: 691-706.

Melo LC, Del Peloso MJ, Pereira HS, Pereira HS, Faria LC, Costa JGC, Diaz JLC, Rava CA, Wendland A and Abreu AFB (2010) BRS Estilo - common bean cultivar with carioca grain upright growth and high yield potential. Crop Breeding and Applied Biotechnology 10: 377-379.

Muller BSF, Sakamoto T, Menezes IPP, Prado GS, Martins WS, Brondani C, Barros EG and Vianello RP (2014) Analysis of BAC-end sequences in common bean (Phaseolus vulgaris L.) towards the development and characterization of long motifs SSRs. Plant Molecular Biology 86: 455-470.

Schmutz J, McClean PE, Mamidi S, Wu GA, Cannon SB, Grimwood J, Jenkins J, Shu S, Song Q, Chavarro C, Torres-Torres M, Geffroy V, Moghaddam SM, Gao D, Abernathy B, Barry K, Blair M, Brick MA, Chovatia M, Gepts P, Goodstein DM, Gonzales M, Hellsten U, Hyten DL, Jia G, Kelly JD, Kudrna D, Lee R, Richard MMS, Miklas PN, Osorno JM, Rodrigues J, Thareau V, Urrea CA, Wang M, Yu Y, Zhang M, Wing RA, Cregan PB, Rokhsar DS and Jackson SA (2014) A reference genome for common bean and genome-wide analysis of dual domestications. Nature Genetics 46: 707-713.

Valdisser PAMR, Mota APS, Bueno LG, Menezes IPP, Coelho GRC, Magalhães FOC and Vianello (2013) Protocolo de extração de DNA e genotipagem de SSRs em larga escala para uso no melhoramento do feijoeiro comum (Phaseolus vulgaris L.). Editora Embrapa, Santo Antônio de Goiás, 6p. (Comunicado Técnico, 208).

Xin Z, Velten J, Oliver MJ and Burke JJ (2003) High-throughput DNA extraction method suitable for PCR. Biotechniques 34: 820-826. 